and also for trivalent arsenic. On account of this the authors are of the opinion that arsenic chloride was formed, the reaction proceeding as follows:

$$
2 \mathrm{As}+{ }_{4} \mathrm{SOCl}_{2}=2 \mathrm{AsCl}_{3}+\mathrm{S}_{2} \mathrm{Cl}_{2}+{ }_{2} \mathrm{SO}_{2} \text {. }
$$

Zinc.-Thionyl chloride appeared to have no action on zinc, either in the cold or after heating for several days at temperatures from I $50-$ $200^{\circ}$.

Cadmium.-Like zinc, cadmium is entirely unacted upon by thionyl chloride either hot or cold.

Magnesium.-A thoroughly cleaned piece of magnesium ribbon was treated with thionyl chloride, but no reaction was found to take place even though the tubes containing the material were heated for many hours at $200^{\circ}$.

Lead, Chromium, Nickel.-These metals were likewise found to be entirely unattacked by the reagent at $200^{\circ}$.

A comparison of some of the above described thionyl chloride reactions with the corresponding sulfuryl chloride reactions is interesting. Iron, as mentioned heretofore, reacts as easily with one as with the other, and the product formed, anhydrous ferric chloride, is the same in both cases when an excess of reagent is used. Again, zinc and cadmium, which are not attacked by sulfuryl chloride, have' been shown likewise to be unattacked by thionyl chloride. With gold, a marked difference is seen. The reaction between gold and sulfuryl chloride proceeds quite readily with the formation of large, red crystals of anhydrous gold chloride, whereas with thionyl chloride, very little reaction was found to take place, even though the tubes were heated for days at $200^{\circ}$.

It is interesting to note that magnesium, zinc and cadmium are not attacked by thionyl chloride whereas mercury, which is also a member of this group of elements, has been previously shown ${ }^{1}$ to react readily with the formation of mercurous and mercuric chloride, depending upon the amount of reagent used.

Rutgers College, NeW Brunswick, N. J.

[From the Department of Clinical Pathology, Columbia University, and tiff Pathological Laboratory of St. I,UKE's Hospital, New York, F. C. WOOD, DIRECTOR.]

\title{
THE DETERMINATION OF IODINE IN THE PRESENCE OF OTHER HALOGENS AND ORGANIC MATTER.
}

\author{
By E. C. Kendall. \\ Received May 4, 1912.
}

During an investigation of the iodine bearing compound of the thyroid gland a method for the determination of small amounts of iodine in organic

${ }^{1}$ This Journal, 32, i 84 (1910). 
combination was worked out in this laboratory. As the reactions involved in this method are quantitative when larger amounts of iodine are present, conditions have been established which furnish a rapid and accurate method for the determination of iodine in the presence of bromides, chlorides and organic matter.

For the determination of iodine when present as an iodide or in the uncombined condition, Andrews ${ }^{1}$ has proposed a volumetric method in which the iodine is converted into iodine chloride by means of iodic acid. The titration by Andrews' method is carried out in the presence of a large excess of hydrochloric acid, the end-point being the disappearance of iodine. As the reaction is limited by the acid to the formation of $\mathrm{ICl}$, one atomic weight of iodine reacts with but two atomic weights of chlorine: $\mathrm{KI}+\mathrm{Cl}_{2}=\mathrm{KCl}+\mathrm{ICl}$.

If the oxidation of the iodine is carried out under conditions which permit the quantitative formation of iodic acid, one atomic weight of iodine requires six atomic weights of chlorine, as shown by the equation

$$
\mathrm{KI}+{ }_{3} \mathrm{Cl}_{2}+{ }_{3} \mathrm{H}_{2} \mathrm{O}=\mathrm{KCl}+\mathrm{HIO}_{3}+{ }_{5} \mathrm{HCl} \text {. }
$$

Dupre's method for the determination of iodine is based upon this reaction, weak chlorine water being used for the oxidation. In a recent paper by Hunter ${ }^{2}$ a method is proposed in which the iodine is oxidized to iodic acid with sodium hypochlorite, and after the removal of the excess of hypochlorite the weight of iodic acid is determined by the further addition of potassium iodide. Iodic acid and potassium iodide react as follows:

$$
\mathrm{HIO}_{3}+{ }_{5} \mathrm{HI}={ }_{3} \mathrm{I}_{2}+{ }_{3} \mathrm{H}_{2} \mathrm{O}
$$

The liberated iodine is titrated with sodium thiosulfate, the weight of iodine titrated being six times the weight originally present.

The method described in this paper is based upon the oxidation of the iodine to iodic acid and the subsequent determination of the amount of iodic acid formed.

\section{Determination of Iodine when Present as an Iodide or Free Iodine.}

For the determination of iodine when present as an iodide or in the uncombined condition, it is necessary to have a solution of the iodine which is free from organic matter or oxidizing agents, such as arsenic, antimony, copper, nitrites and all compounds which liberate iodine from potassium iodide. If bromine or any compounds which interfere are present, the method is modified as described below.

The solution containing the iodine is placed in a $500 \mathrm{cc}$. flask, the total volume of the solution being between 200 and $250 \mathrm{cc}$. The solution ${ }^{3}$

1 This Journat, 25, 756 .

3 . Biol. Chem., 7, 321 (1910).

- To prevent loss of iodine at this point the solution must be cold, and when more than roo $\mathrm{mg}$. of iodine are present the solution in the flask should be covered with a few cubic centimeters of benzene. 
should have a neutral or very slightly alkalin reaction. Five cc. of phosphoric acid ( $85 \%$ diluted with an equal volume of water) are added to the solution. A solution of sodium hypochlorite ${ }^{1}$ is now added while the solution is shaken with a rotary motion. If an iodide is present iodine will be liberated, but the further addition of hypochlorite will oxidize this to iodic acid. The hypochlorite should be added slowly and care should be taken to avoid adding more than is necessary to give a colorless solution. The solution is allowed to stand for two to three minutes after becoming colorless to insure the complete oxidation of the iodine and then Io cc. of a colorless $5 \%$ solution of phenol are added. The phenol combines with the free chlorine in solution, forming chlorphenol. This compound being non-ionized removes all traces of chlorine: from the sphere of reaction. When a solution of phenol is slowly added to a solution containing free chlorine, the phenol is partially oxidized, producing colored compounds, but if the phenol is all added at once, the chlorine adds to the benzene ring without oxidation of the phenol. For this reason the phenol is added to the flask as rapidly as possible. This is accomplished by forcing the phenol with the breath from a ro cc. pipet from which the tip has been removed, so that the delivery is from an opening which is the same bore as the rest of the tube. After shaking the solution with a rotary motion and blowing out any traces of chlorine gas with the breath, a few drops of phenolphthalein are added, and the solution is made slightly alkalin with $30 \%$ sodium hydroxide which is free from nitrites. The solution is now made acid with ro cc. of $50 \%$ phosphoric acid. Upon the addition of potassium iodide the iodic acid in solution will liberate iodine, which is titrated with sodium thiosulfate. The amount of potassium iodide added should be sufficient to leave an excess after reacting with the iodic acid. The weight of potassium iodide required is roughly eight times the weight of the iodine originally present.

The most satisfactory results are obtained by standardizing the sodium thiosulfate which is used to titrate the iodine liberated by the iodic acid under the conditions which obtain in the determinations. Ten grams of freshly resublimed iodine are weighed out in a weighing bottle. This is placed in a large Erlenmeyer flask containing 5-10 grams of sodium hydroxide dissolved in 400-500 cc. of water. The cover is removed from the bottle and the iodine is dissolved in the alkali. The solution is now diluted to 2 liters; I cc. will contain $5 \mathrm{mg}$. of iodine. For standardizing, the iodine solution is measured into a flask, the volume is made between

${ }^{1} \mathrm{~A}$ convenient means of preparing this reagent in a proper concentration is to add II 2 grams of calcium hypochlorite, whose available chlorine is approximately $35 \%$, to $1200 \mathrm{cc}$. of water. Stir the mixture to break up any lumps and heat to boiling. One hundred grams of anhydrous sodium carbonate are now added and the solution boiled 5-10 minutes. After cooling, the precipitate of calcium carbonate is filtered and the solution of sodium hypochlorite is kept in a black bottle. 
200 and $250 \mathrm{cc}$, and then the acid and hypochlorite are added as described above. The weight of iodine measured into the flask divided by the number of cubic centimeters of thiosulfate is the standard of the sodium thiosulfate for the iodine originally present. ${ }^{1}$ If more than too $\mathrm{mg}$. of iodine are present there is danger of loss of iodine by volatilization during the titration. A satisfactory means of preventing this is to add a few cubic centimeters of benzene to the flask. This will float on the surface and prevent loss of iodine. Care should be taken to finish the titration with starch and to shake the solution vigorously when near the end-point.

By the method described above the following results were obtained. The iodine was present in the form of potassium iodide which was prepared by dissolving a known weight of pure iodine in potassium hydroxide and reducing with metallic aluminium.

$\begin{array}{cccc}\text { Iodine taken. } & \text { Iodine found. } & \text { Error, mg. } & \text { Error, per cent. } \\ 5.079 & 5.077 & -0.002 & 0.04 \\ 5.079 & 5.040 & -0.039 & 076 \\ 7.618 & 7.619 & 0.001 & 0.01 \\ 7.618 & 7.630 & 0.012 & 0.15 \\ 10.158 & 10.136 & -0.022 & 0.22 \\ 10.158 & 10.150 & -0.008 & 0.08 \\ 12.698 & 12.717 & 0.019 & 0.15 \\ 12.698 & 12.707 & 0.009 & 0.07 \\ 15.237 & 15.166 & -0.071 & 0.70 \\ 15.237 & 15.213 & -0.024 & 0.16 \\ 17.776 & 17.742 & -0.034 & 0.19 \\ 17.77 & 17.756 & -0.020 & 0.11 \\ 20.316 & 20.337 & 0.021 & 0.10 \\ 20.315 & 20.394 & 0.078 & 0.38 \\ 2.855 & 22.820 & -0.035 & 0.15 \\ 22.855 & 22.871 & 0.016 & 0.07 \\ 25.395 & 25.434 & 0.039 & 0.15 \\ 25.395 & 25.340 & -0.055 & 0.22 \\ 30.06 & 30.13 & 0.07 & 0.23 \\ 30.06 & 30.13 & 0.07 & 0.23 \\ 40.08 & 40.10 & 0.02 & 0.05 \\ 40.08 & 40.10 & 0.02 & 0.05 \\ 50.10 & 50.17 & 0.07 & 0.13 \\ 50.10 & 50.30 & 0.20 & 0.39 \\ 60.12 & 60.07 & -0.05 & 0.09 \\ 60.12 & 60.26 & 0.14 & 0.23 \\ 70.14 & 70.19 & 0.04 & 0.05 \\ 70.14 & 70.27 & 0.14 & 0.20 \\ 80.16 & 80.19 & 0.03 & 0.04 \\ & & & \end{array}$

1 The iodine equivalent of sodium thiosulfate in this titration for iodine originally present is one-sixth the amount found by the titration. Hence if $0.1 N$ thiosulfate is used the standard will be approximately $2.115 \mathrm{mg}$. of original iodine per cubic centimeter. 


$\begin{array}{cccc}\text { Iodine taken. } & \text { Iodine found. } & \text { Error, mg. } & \text { Error, per cent. } \\ 80.16 & 80.11 & -0.05 & 0.06 \\ 90.18 & 90.20 & 0.02 & 0.02 \\ 90.18 & 90.39 & 0.21 & 0.23 \\ 100.20 & 100.12 & -0.08 & 0.08 \\ 100.20 & 99.74^{1} & -0.46^{1} & 0.46 \\ 125.45 & 125.65 & 0.20 & 0.16 \\ 125.45 & 125.45 & 0.00 & 0.00 \\ 150.57 & 150.62 & 0.05 & 0.03 \\ 150.57 & 150.54 & -0.03 & 0.02 \\ 150.57 & 150.54 & -0.03 & 0.02 \\ 175.66 & 175.80 & 0.14 & 0.08 \\ 175.66 & 175.59 & -0.07 & 0.04 \\ 200.71 & 200.80 & 0.09 & 0.04 \\ 200.71 & 200.76 & 0.05 & 0.02 \\ 225.85 & 225.53 & -0.32 & 0.15 \\ 225.85 & 226.00 & 0.15 & 0.07 \\ 250.95 & 250.91 & -0.04 & 0.02 \\ 250.95 & 250.91 & -0.04 & 0.02 \\ 276.04 & 275.88 & -0.16 & 0.06 \\ 276.04 & 276.12 & 0.08 & 0.03 \\ 301.14 & 301.45 & 0.31 & 0.10 \\ 301.14 & 301.05 & -0.09 & 0.03 \\ 326.23 & 326.02 & -0.21 & 0.07 \\ 326.23 & 326.02 & -0.21 & 0.07 \\ 351.33 & 350.78 & -0.55 & 0.15 \\ & & & \end{array}$

Determination of Iodine in the Presence of Bromides and Chlorides.

When bromine or a bromide is present in a solution to which hypochlorite is added, there is no oxidation of the bromine similar to the oxidation of iodine. Furthermore, the presence of the bromine does not interfere with the oxidation of the iodine. Hydrobromic acid when present in large amount will reduce iodic acid, but all hydrobromic acid may be removed by the addition of sufficient sodium hypochlorite.

The method for the determination of iodine in the presence of bromine is as follows: The iodine (in the form of iodide or uncombined) is dis solved in $200-250 \mathrm{cc}$. of water having a neutral or slightly alkalin solution. Five cc. of phosphoric acid $(85 \%$ diluted with an equal volume of water) and ro cc. of benzene are added. Sufficient sodium hypochlorite is now added to liberate all of the bromine and oxidize the iodine. Iodine will be liberated at first, but this will be further oxidized to iodic acid. It is imperative that all the bromine be liberated. A small amount of powdered pumice is added and the solution boiled. The benzene reacts with the hypobromite and hypochlorite, forming brom- and chlorbenzene. The free bromine boils out of solution. A precipitate of brombenzene may form but this does not affect subsequent operations. After a few

1 Iodine was lost as no benzene covering was used in this titration. 
minutes boiling the solution will be colorless and all traces of bromine removed. The solution is now cooled. Under these conditions it is not necessary to neutralize and acidify, but the potassium iodide is added directly to the cold solution. A cover of benzerie should be used for weights of iodine over roo mg.

The following results show that there is no appreciable interference of the bromine in the determination of iodine by this method.

$$
\begin{aligned}
& 50 \mathrm{mg} \text {. iodine and no } \mathrm{KBr} \text { required } 26.38 \mathrm{cc} . \mathrm{Na}_{2} \mathrm{~S}_{2} \mathrm{O}_{3} \\
& 50 \mathrm{mg} \text {. iodine and o.1 gram } \mathrm{KBr} \text { required } 26.38 \mathrm{cc} . \mathrm{Na}_{2} \mathrm{~S}_{2} \mathrm{O}_{3} \\
& 50 \mathrm{mg} \text {. iodine and } 0.5 \mathrm{gram} \mathrm{KBr} \text { required } 26.30 \mathrm{cc} . \mathrm{Na}_{2} \mathrm{~S}_{2} \mathrm{O}_{3} \\
& 50 \mathrm{mg} \text {. iodine and } \mathrm{I} .0 \text { gram } \mathrm{KBr} \text { required } 26.30 \mathrm{cc} . \mathrm{Na}_{2} \mathrm{~S}_{2} \mathrm{O}_{3} \\
& \text { Ioo } \mathrm{mg} \text {. iodine and no } \mathrm{KBr} \text { required } 20.50 \mathrm{cc} . \mathrm{Na}_{2} \mathrm{~S}_{2} \mathrm{O}_{3} \\
& \text { Ioo } \mathrm{mg} \text {. iodine and } 0.1 \text { gram } \mathrm{KBr} \text { required } 20.48 \mathrm{cc} . \mathrm{Na}_{2} \mathrm{~S}_{2} \mathrm{O}_{3} \\
& \text { IoO } \mathrm{mg} \text {. iodine and } 0.5 \text { gram } \mathrm{KBr} \text { required } 20.50 \mathrm{cc} . \mathrm{Na}_{2} \mathrm{~S}_{2} \mathrm{O}_{3} \\
& \text { Ioo } \mathrm{mg} \text {. iodine and I. o gram } \mathrm{KBr} \text { required } 20.48 \mathrm{cc} \text {. } \mathrm{Na}_{2} \mathrm{~S}_{2} \mathrm{O}_{3} \\
& 250 \mathrm{mg} \text {. iodine and no } \mathrm{KBr} \text { required 46. Io cc. } \mathrm{Na}_{2} \mathrm{~S}_{2} \mathrm{O}_{3} \\
& 250 \mathrm{mg} \text {. iodine and } \mathrm{O} . \mathrm{I} \text { gram } \mathrm{KBr} \text { required } 46.00 \mathrm{cc} \text {. } \mathrm{Na}_{2} \mathrm{~S}_{2} \mathrm{O}_{3} \\
& 250 \mathrm{mg} \text {. iodine and } 0.5 \text { gram } \mathrm{KBr} \text { required } 46.15 \mathrm{cc} . \mathrm{Na}_{2} \mathrm{~S}_{2} \mathrm{O}_{3} \\
& 250 \mathrm{mg} \text {. iodine and } \mathrm{r} \text {.o gram } \mathrm{KBr} \text { required } 45.88 \mathrm{cc} \text {. } \mathrm{Na}_{2} \mathrm{~S}_{2} \mathrm{O}_{3}
\end{aligned}
$$

In standardizing the sodium thiosulfate to be used when bromine is present, more satisfactory results are obtained by establishing the standard with a known weight of the iodine solution as prepared above, under the conditions which are described for the determination of iodine in the presence of bromine.

The presence of chlorides has no effect upon the determination of iodine by this method and there is no need of boiling the solution. The following results bear on this point:

$$
\begin{aligned}
& 50 \mathrm{mg} \text {. iodine and no } \mathrm{NaCl} \text { required } 26.50 \mathrm{cc} . \mathrm{Na}_{2} \mathrm{~S}_{2} \mathrm{O}_{3} \\
& 50 \mathrm{mg} \text {. iodine and } 1.0 \text { gram } \mathrm{NaCl} \text { required } 26.50 \mathrm{cc} . \mathrm{Na}_{2} \mathrm{~S}_{2} \mathrm{O}_{3} \\
& 50 \mathrm{mg} \text {. iodine and } 5.0 \text { gram } \mathrm{NaCl} \text { required } 26.5 \mathrm{I} \mathrm{cc.} \mathrm{Na}_{2} \mathrm{~S}_{2} \mathrm{O}_{3} \\
& 50 \mathrm{mg} \text {. iodine and 10.0 gram } \mathrm{NaCl} \text { required 26.50 cc. } \mathrm{Na}_{2} \mathrm{~S}_{2} \mathrm{O}_{3}
\end{aligned}
$$

These results were obtained by the method outlined under the heading "Determination of Iodine when Present as Iodide or Free Iodine."

When iodine is to be determined in the presence of organic matter or nitrites, copper, iron, mercury and silver, it is necessary to remove these interfering substances and prepare the iodine as an iodide for the determination.

\section{Determination of Iodine in the Presence of Organic Matter and Interfer- ing Elements.}

The most satisfactory means of removing the above mentioned substances is by a fusion which will destroy organic matter, retain the iodine as iodide and, by forming insoluble compounds, remove interfering elements. 
Many fusion ${ }^{1}$ mixtures have been proposed for the destruction of organic matter, but these when tried did not give entirely satisfactory results for the peculiar needs of this method. Satisfactory results for the determination of iodine in the presence of organic material may be obtained as follows:

\section{Detailed Description of Method.}

The compound to be analyzed is placed in $\mathrm{a}^{3} / \mathrm{s}$ inch nickel crucible, and is dissolved in $2-3 \mathrm{cc}$. of $30 \%$ sodium hydroxide solution and 5 grams, weighed to within \pm 0.25 gram, of stick sodium hydroxide. The amount of substance to be taken depends upon the chemical properties of the compound, but it is best to take sufficient to yield $50-75 \mathrm{mg}$. of iodine unless this will require more than I gram of substance. The contents of the crucible are heated on a hot plate to a pasty consistency. This

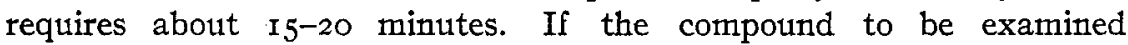
is an oil (as iodized sesame oil) it will be found more convenient to use alcohol instead of water. The crucible is now heated in the following manner. One-quarter inch of sand is placed in the bottom of a $3^{1 / 4}$ inch nickel crucible. The crucible is placed on a triangle over a large Bunsen burner, and is surrounded by a collar of sheet asbestos. The asbestos collar is $1 / 4$ inch thick, $3^{3} / 4$ inches in diameter, and $3^{1 / 2}$ inches high. The hot gases from the burner are thus made to pass around the side of the crucible before escaping.

After heating the crucible until it has a dull red heat, the $2^{3} / \mathrm{s}$ inch crucible is placed inside the larger crucible resting on the sand.

The contents of the crucible melt and give off gases which may cause foaming. If foaming occurs a gentle blast of air is allowed to play over the foaming contents of the crucible. This will break the foaming and prevent the melt from creeping up the sides of the crucible.

As soon as the contents cease burning and foaming and settle down to the bottom of the crucible, the small crucible is removed with forceps and shaken with a rotary motion. This cools the crucible and prevents separation of carbon in large particles. The fusion melt is now a brown liquid with small particles of carbon floating on the surface. The crucible is again placed in the large crucible and a very small amount of finely ground potassium nitrate is added. This will oxidize the separated

${ }_{1}$ The fusion method described in this paper is the result of many attempts to find a fusion which will retain all of the iodine and permit the subsequent volumetric determination of the iodine. Lack of space prevents the recording of many results which have been obtained during the course of the investigation, but it is the experience of the writer that no fusion method will give quantitative results with large amounts of iodine if the fusion melt is heated to a red heat. Fusions with alkali carbonates may be made with small amounts of iodine and the fusion melt heated to a strong red heat without apparent loss, but when this method is tried with large amounts it is very evident that serious loss of iodine occurs. 
carbon and dissolved organic matter. Small amounts of nitrate are added from the tip of a spatula until the melt settles to the bottom of the crucible and ceases to give off bubbles of gas. The melt must be clear and must not be opaque or white. The heat should be sufficient to prevent the fusion mass from cooling on the sides of the crucible, but it must not be great enough to volatilize any of the sodium hydroxide. The crucible must not become even dull red, as loss of iodine may occur.

If a large amount of organic matter is present carbon may separate in large particles. In this case there will be a slight liberation of bubbles around the particles of carbon, but the remainder of the melt should be clear and free from bubbles.

With compounds such as iodized protein the fusion requires but two to three minutes, as little separation of carbon occurs and the addition of a small amount of nitrate immediately clears up the brown fusion mass removing all brown color. With oil and compounds which liberate carbon some particles may remain after addition of the nitrate, but this does not affect the accuracy of the results.

The melt is allowed to cool on the sides of the crucible. When cold the crucible is nearly filled with water and placed on a hot plate. The melt dissolves readily. The solution of the fusion mass is transferred to a beaker and then to a $500 \mathrm{cc}$. Erlenmeyer flask. The volume should be between $200-250 \mathrm{cc}$. If some element interfering with the determination, as silver, iron, mercury or copper, is present, it is removed by making the volume $250 \mathrm{cc}$. and filtering into a $200 \mathrm{cc}$. flask, washing out the flask with the first $15-20 \mathrm{cc}$. of solution. If no interfering element is present, there is no need of filtering.

The solution contains sodium hydroxide and carbonate, sodium iodide, and potassium nitrite and nitrate. When this is acidified the hydriodic acid will reduce the nitrous acid and iodine will be liberated.

In order to prevent loss of iodine with the escaping carbon dioxide, sodium bisulfite is added. This will reduce the iodine to hydriodic acid which will be retained in solution.

To the cold solution from the fusion mass $2 \mathrm{cc}$. of a $10 \%$ solution of sodium bisulfite and a few cubic centimeters of chloroform are added and the solution is shaken with a rotary motion. Ten cc. of $50 \%$ sulfuric acid are added, by allowing a ro cc. pipet to deliver the acid directly into the flask. The acid should be added cautiously and the solution should be well shaken between additions. The chloroform prevents foaming with the liberated carbon dioxide. If there is any liberation of iodine, $0.5 \mathrm{cc}$. more of the sulfite solution is added and the acidification is continued. The liberation of iodine shows the presence of an excess of nitrous acid. While there is no error caused by a large amount of nitrite in the solution, provided sufficient sulfite is added, best results are obtained 
by keeping the excess as small as possible, and $2 \mathrm{cc}$. of $10 \%$ sodium bisulfite should be sufficient to reduce the iodine liberated.

The iodine is now present as hydriodic acid and is determined by adding sodium hypochlorite until the iodine is oxidized to iodic acid. Ten cc. of phenol are added and then the solution is made slightly alkalin to phenolphthalein with $30 \%$ sodium hydroxide free from nitrites. Acidify with $5 \mathrm{cc}$. of $50 \%$ phosphoric acid, add potassium iodide and titrate the iodine with sodium thiosulfate. The hypochlorite oxidizes all nitrous acid to nitric acid which cannot liberate iodine in the presence of the slight acidity furnished by the phosphoric acid.

The Io cc. of $50 \%$ sulfuric acid which are used will neutralize the alkali and leave a proper acidity for the oxidation with hypochlorite and removal of the free chlorine with phenol. If the solution is warm during the addition of the acid and $2 \mathrm{cc}$. of sulfite solution are not sufficient to reduce the iodine, some iodine may be lost by volatilization; it is therefore better to have the solutions cold during acidification.

This same method of fusion may be applied to larger amounts of organic material by using a larger crucible and more sodium hydroxide. ${ }^{1}$

To show the accuracy of this method of fusion IOO mg. of potassium iodide were added to a crucible containing 0.5 gram of Witte peptone. The sodium hydroxide was added as described above, and after fusion and solution in water the following results were obtained.

The titration of five determinations required $39.40,39.42,39.35,39.40$, $39.38 \mathrm{cc}$. of thiosulfate. Determination of iodine in $100 \mathrm{mg}$. of potassium iodide without fusion required $39.4 \mathrm{I} \mathrm{cc}$. of thiosulfate.

The method as described is accurate for the determination of iodine in the presence of bromine. In this case the fusion is the same. To the cold solution of the fusion mass $2 \mathrm{cc}$. of Io\% sodium bisulfite are added and the solution is acidified with $15 \mathrm{cc}$. of $85 \%$ phosphoric acid. Sodium hypochlorite is added until all bromine is liberated and the iodine is oxidized to iodic acid. Ten cc. of benzene are now added and the solution is boiled 8-1o minutes. All traces of chlorine and bromine are removed by combining with the benzene, and the iodic acid in solution is determined by addition of potassium iodide to the cold solution, and titration of the liberated iodine. It is not necessary to neutralize and acidify before addition of potassium iodide when the solution has been boiled.

For the determination of iodine in pure organic compounds the method of fusion proposed by Pringsheim ${ }^{2}$ may be used in place of the fusion described in this paper. The solution of the fusion is boiled 5-ro minutes,

${ }^{1}$ If an unknown weight of sodium hydroxide is present it may be neutralized using methyl orange as indicator. Three or $4 \mathrm{cc}$. of $50 \%$ sulfuric acid should be added in excess of the neutral point.

${ }^{2}$ Pringsheim, Ber., 36, 4244; 38, 2459. 
and cooled. Four cc. of $10 \%$ sodium bisulfite and a few drops of methyl orange are added. The solution is now acidified with $50 \%$ sulfuric acid. If any traces of iodine are liberated and are not reduced by the bisulfite, more bisulfite is added and the acidification continued. After the solution is made slightly acid to methyl orange the hypochlorite is added and the method carried out as described above. If bromine is present the solution is acidified with $85 \%$ phosphoric acid in place of the sulfuric acid, and then the method described above for the determination of iodine in the presence of bromine is followed.

For a comparison of the iodine content determined in this manner and by other methods, samples of typical organic compounds containing iodine were analyzed, with the following results:

\begin{tabular}{|c|c|c|c|c|}
\hline Substance. & $\begin{array}{l}\text { Wt. taken. } \\
\text { Gram. }\end{array}$ & $\begin{array}{l}\text { Mg. AgI found } \\
\text { or cc. thio- } \\
\text { sulfate required. }\end{array}$ & $\begin{array}{l}\text { Iodine } \\
\text { found. }\end{array}$ & $\begin{array}{l}\text { Per cent. } \\
\text { iodine. }\end{array}$ \\
\hline \multirow{5}{*}{ Iodized oil, olio iodate } & 0.2348 & $104.0 \mathrm{mg} . \mathrm{AgI}$ & $56.21 \mathrm{mg}$. & $23 \cdot 94^{1}$ \\
\hline & 0.3954 & $4^{8} \cdot 7^{8 \mathrm{cc}}$ & $94.43 \mathrm{mg}$. & $23.88^{2}$ \\
\hline & 0.3767 & $47.0 \mathrm{cc}$ & $90.99 \mathrm{mg}$. & $24 \cdot 15^{2}$ \\
\hline & $0.284 \mathrm{I}$ & $34.60 \mathrm{cc}$. & $67.82 \mathrm{mg}$. & $23.87^{2}$ \\
\hline & 0.3255 & $39.78 \mathrm{cc}$ & $77.97 \mathrm{mg}$. & $23.95^{2}$ \\
\hline \multirow{6}{*}{ Iodized protein iodalbin. } & 0.4595 & $187.0 \mathrm{mg} . \mathrm{AgI}$ & $101.07 \mathrm{mg}$. & $21.99^{3}$ \\
\hline & 0.4000 & $44 \cdot 75 \mathrm{cc}$ & $87.71 \mathrm{mg}$ & $2 \mathrm{I} \cdot 93^{3}$ \\
\hline & 0.4000 & $44.5^{8} \mathrm{cc}$ & $87.38 \mathrm{mg}$. & $21.84^{2}$ \\
\hline & 0.4000 & $45.50 \mathrm{cc}$ & $88.08 \mathrm{mg}$. & $22.02^{2}$ \\
\hline & 0.400 & $45.43 \mathrm{cc}$. & $87.95 \mathrm{mg}$. & $21.99^{2}$ \\
\hline & 0.4000 & $45.55 \mathrm{cc}$ & 88. I $\leq \mathrm{mg}$. & $22.05^{2}$ \\
\hline \multirow{5}{*}{$\begin{array}{l}\text { Iodine in organic combination } \\
\text { with benzene ring, formi- } \\
\text { dine } \mathrm{C}_{29} \mathrm{H}_{15} \mathrm{O}_{8} \mathrm{I}_{5} \text {. }\end{array}$} & 0.2495 & $204.0 \mathrm{mg} . \mathrm{AgI}$ & $110.26 \mathrm{mg}$. & $44 \cdot 19^{1}$ \\
\hline & 0.3364 & $282.7 \mathrm{mg} \cdot \mathrm{AgI}$ & $\mathrm{I} 52.79 \mathrm{mg}$. & $43.84^{1}$ \\
\hline & 0.2084 & $44.47 \mathrm{cc}$ & $91.61 \mathrm{mg}$. & $43 \cdot 96^{8}$ \\
\hline & 0.2698 & $57.55 \mathrm{cc}$. & I I $8.55 \mathrm{mg}$. & $43 \cdot 94^{2}$ \\
\hline & 0.2550 & $54.60 \mathrm{cc}$ & $\mathrm{II} 2.48 \mathrm{mg}$. & $44 . \mathrm{II}^{2}$ \\
\hline \multirow{3}{*}{ Another sample of formidine. } & 0.2153 & $223.0 \mathrm{mg} . \mathrm{AgI}$ & $\mathrm{I} 20,53 \mathrm{mg}$. & $55 \cdot 98^{1}$ \\
\hline & 0.2336 & $63.70 \mathrm{cc}$ & $\mathrm{I} 3 \mathrm{I} .22 \mathrm{mg}$. & $56.17^{8}$ \\
\hline & 0.3220 & $87.75 \mathrm{cc}$ & I $80.76 \mathrm{mg}$. & $56.14^{2}$ \\
\hline \multirow{4}{*}{ Commercial dye erythrosin. } & 0.5375 & I $5.55 \mathrm{cc}$. & $32.03 \mathrm{mg}$ & $5 \cdot 96^{2}$ \\
\hline & 0.5747 & $16.31 \mathrm{cc}$ & $33.59 \mathrm{mg}$. & $5.84^{2}$ \\
\hline & 0.4235 & $12.60 \mathrm{cc}$ & $25.86 \mathrm{mg}$. & $6.10^{8}$ \\
\hline & $0.577^{2}$ & I $6.73 \mathrm{cc}$. & $34.46 \mathrm{mg}$. & $5 \cdot 97^{5}$ \\
\hline
\end{tabular}

1 Fused by method of Pringsheim and iodine determined gravirnetrically.

2 Fused and iodine determined by this method.

Iodine determined by Carius tube method.

- This is an impure sample of formidine.

- Fused by method of Pringsheim, but rest of determination by this method.

- This dye contained bromine. No determination of the bromine was made. 


\section{The Determination of Small Quantities of Iodine in Organic Combination.}

In I9 Io Hunter ${ }^{1}$ published a method for the determination of small quantities of iodine in organic combination, which may be briefly stated as follows: The compound is fused with a mixture of sodium potassium carbonate and potassium nitrate. This fusion destroys the organic matter and fixes the iodine as an iodide. The fusion mass is dissolved in water and sodium hypochlorite is added. Upon acidification with phosphoric acid the sodium hypochlorite oxidizes the nitrous acid formed during the fusion to nitric acid and the iodide is oxidized to iodic acid. The excess of free chlorine formed from the sodium hypochlorite is removed by boiling. After all free chlorine has been removed and the solution is cold, potassium iodide is added. The iodic acid in solution, which was obtained from the iodine originally in organic combination, reacts with the added potassium iodide, each weight of iodine present as iodic acid liberating six times its weight of iodine. The weight of iodine finally titrated, therefore, is equivalent to six times the amount of iodine originally present.

During the past eighteen months the writer has had oceasion to make determinations of iodine in thyroid preparations, and the method outlined above was used for this work. As the results obtained were not entirely satisfactory, a careful study of the chemical reactions involved was undertaken with the hope of finding a reliable method for the determination of iodine. The one serious and unavoidable objection to Hunter's method is the fact that simply boiling a solution containing a large amount of sodium hypochlorite, to which phosphoric acid has been added, will not always completely remove compounds which liberate iodine from potassium iodide. ${ }^{2}$

Foerster and Jorre ${ }^{3}$ have pointed out that when a solution of sodium hypochlorite is acidified, oxy-chlorine compounds, among which may be chloric acid, are produced. The amount of chloric acid formed appears to depend upon the rate of acidification, the temperature, and concentration of the acid used.

In Hunter's method it is necessary to add the phosphoric acid to the solution containing a comparatively large amount of sodium hypochlorite. This results in the formation of oxy-chlorine acids, which for a series of determinations may vary between wide limits depending upon the conditions of the fusion and acidification. When the solution is boiled for I 5-20 minutes these acids are broken down and expelled, but rarely are

'Hunter, J. Biol. Chem., 7, 321 (1910).

${ }^{2}$ In this connection Hunter says: "The reagent that gives most frequent trouble is the hypochlorite solution. It must be reasonably fresh. If this condition be fulfilled the commercial product of ten gives excellent results. Sometimes, however, it is impossible to get a commercial solution that does not give values too high."

J. prakt. Chem., [2] 59, 53 (1899). 
they entirely removed from solution. As the amount of oxidizing compounds formed in the solution is uncertain, and as a variable amount may be removed by boiling, no constant correction can be applied to the results. For large amounts of iodine this correction is inappreciable, but when only a few hundredths of a milligram are present it is a serious objection. The chemical properties of chloric acid are closely analogous to those of iodic acid, and while some compounds will reduce one more easily and completely than the other, no single compound was found which could be satisfactorily used in a quantitative method to destroy chloric and leave the iodic acid unchanged. Although many attempts were made to modify Hunter's method by removing all oxidizing compounds except iodic acid, no satisfactory modification was found.

Further investigation, however, has resulted in the following method for the determination of iodine, which has proved reliable in this laboratory.

The method for small amounts of iodine is carried out as for larger amounts described above with the following modifications: When preparations of the thyroid gland are analyzed it is best to use a I-gram sample in order to furnish sufficient iodine to give an accurate buret reading. With $\mathrm{I}$ gram of thyroid substance 5 grams of sodium hydroxide are insufficient to give a fusion which will remain liquid in the presence of the carbonates formed during the fusion. For this reason Io grams of sodium hydroxide are used. One gram of the thyroid preparation is placed in a $2^{3} / \mathrm{s}$ inch nickel crucible to which are added Io grams of sodium hydroxide and 5-6 cc. of $30 \%$ sodium bydroxide. All water is evaporated off on a hot plate, and the crucible is placed inside the $31 / 4$ inch nickel crucible which has $1 / 4$ inch layer of sand on the bottom, and is heated to a dull red heat. Foaming of the contents of the small crucible is checked by playing over the surface of the foam with a gentle air blast. ${ }^{1}$ As soon as the melt settles to the bottom, the small crucible is removed with crucible tongs and partially cooled by agitating the contents with a rotary motion. The crucible is again placed in the larger crucible and small amounts of potassium nitrate are added until no more bubbles are given off (except around large particles of separated carbon). The melt should be clear and not white.

As soon as sufficient nitrate is added to oxidize all but the large particles of carbon the excess of nitrate and the nitrite formed is reduced ${ }^{2}$ by the addition of small amounts of gallic acid to the fusion melt. Gallic acid is

${ }^{1}$ Under some conditions it is necessary to break the foaming with the flame from a second Bunsen burner.

2 The nitrate and nitrite are reduced before solution in order to prevent the production of large amounts of hydrobromic acid when bromine is added to oxidize the iodine to iodic acid. This step is not necessary when a large amount of iodine is present and hypochlorite is used to oxidize the iodine. 
easily decomposed and acts as a vigorous reducing agent. The first addition of gallic acid will liberate a large amount of bubbles and will be destroyed without the separation of much carbon. As more gallic acid is added the action is less vigorous and carbon will separate at first but will be burned rapidly. The gallic acid should be added until there is a decided separation of carbon. The crucible is now heated for a short time to insure the destruction of the gallic acid. The melt should be clear and should liberate no bubbles except to a slight extent around the edge.

The melt is allowed to cool on the sides of the crucible. The crucible is nearly filled with water and is placed on a hot plate. When the fusion mass is dissolved it is transferred to a beaker and then to a $500 \mathrm{cc}$. Erlenmeyer flask. It should' be a colorless, clear solution except for particles of separated carbon which sometimes escape oxidation. If the solution is brown it indicates the presence of an excess of gallic acid. The volume should be $200-250 \mathrm{cc}$. To the solution of the fusion mass a few cubic centimeters of chloroform and I cc. of Io\% sodium bisulfite are added. $^{1}$ The solution is colored with a few drops of methyl orange and then $85 \%$ phosphoric acid is added by allowing the acid to run directly into the flask from the pipet. The flask is vigorously shaken with a rotary motion to expel the carbon dioxide. There must be no liberation of iodine at this point. Two or $3 \mathrm{cc}$. of acid are added after the indicator has changed color. A few drops of bromine ${ }^{2}$ are now added from a dropping bottle. The solution is shaken with a rotary motion until the bromine imparts a distinctly reddish color to the solution." The solution is now boiled 8-10 minutes, when all color of bromine is expelled.

To the boiling solution, which should be colorless, 15-20 drops of sodium

${ }^{1}$ An excess of sulfite is to be avoided as it produces hydrobromic acid from the bromine, and this may reduce the iodic acid, giving low results. The one cubic centimeter is added to make certain that no iodine is lost by traces of nitrite which may escape reduction.

${ }^{2}$ When more than 10-12 mg. of iodine are present, bromine should not be used as the hydrobromic acid produced during the oxidation of the iodine may reduce the iodic acid when the solution is boiled. For amounts of iodine above ro-12 mg. sodium hypochlorite is used in place of the bromine. The hypochlorite is added until the iodine is oxidized to iodic acid; the solution is boiled 8-Io minutes; IO-15 drops of $5 \%$ sodium salicylate are added; the solution is cooled; and the iodic acid is determined with potassium iodide and thiosulfate. When hypochlorite is used it is not necessary to reduce the nitrite with gallic acid, but $2 \mathrm{cc}$. of sodium bisulfite should be used. Bromine in the cold will not quantitatively oxidize iodine to iodic acid but when the solution is boiled the iodine is completely converted into iodic acid. Bromine is used for the small weights of iodine as it can be completely removed from solution. However, bromine cannot be used for weights of iodine above IO-I $2 \mathrm{mg}$. with certainty and when iodine is present in this amount there is no appreciable error caused by the use of sodium hypochlorite for oxidation of the iodine.

The bromine will destroy the color of the methyl orange. 
salicylate ${ }^{1}$ solution are added. The salicylic acid produced in solution will remove all traces of bromine but will not affect the iodic acid. After boiling I-2 minutes after the addition of the salicylate, the solution is cooled, potassium iodide is added and the liberated iodine is titrated ${ }^{2}$ with thiosulfate. ${ }^{3}$

In using this method for a qualitative test for the determination of iodine it is necessary to use reagents of known purity. A blank should be made using some organic substance free from iodine. If no iodine is present a perfect blank will result, and as little as $0.005 \mathrm{mg}$. of iodine can be detected with certainty. It is also possible to replace the nitrate with chlorate as an oxidizing agent. With small amounts of organic matter the results are the same as when nitrate is used. However, the chlorate does not oxidize as completely as the nitrate and low results may be obtained unless care is exercised. As the use of chlorate requires more attention and experience on the part of the operator its use is not advised.

To show the accuracy of this method solutions of iodine were measured into $2^{3} / \mathrm{s}$ inch nickel crucibles containing the weights of iodine given below. The water was evaporated, 0.5 gram of Witte's peptone was

1 This is best prepared by dissolving 5 grams of pure salicylic acid in sodium hydroxide and diluting to approximately IOO $\mathrm{ec}$.

2 Hunter recommends a clear $0.5 \%$ solution of arrowroot starch for an indicator in finishing the titration. A $0.5 \%$ solution of Kahlbaum's soluble starch also furnishes a sensitive indicator for this work.

3 The most convenient strength of sodium thiosulfate for amounts of iodine ranging from $0.5-5.0 \mathrm{mg}$. is $0.005 \mathrm{~N}$. This is not a stable solution and must be frequently restandardized. A convenient method proposed by Hunter is to prepare a solution of potassium acid iodate which is equivalent to a known weight of iodine. The strength of any sample of thiosulfate is readily found by titrating the iodine liberated by the acid iodate solution, which retains its strength indefinitly. The iodine equivalent of the potassium iodate is found as follows: Prepare an o. I $N$ solution of potassium acid iodate $\mathrm{KIO}_{3} \cdot \mathrm{HIO}_{3}$ by dissolving 3.249 grams of he salt in one liter of water. This solution diluted twenty times will be approximately $0.005 \mathrm{~N}$. Dissolve a known weight of pure iodine (approximately $\mathrm{I}$ gram) in one liter of water containing $\mathrm{I}-2$ grams of sodium hydroxide. Dilute this ten times. One $\mathrm{cc}$. of this solution will contain $0 . \mathrm{rmg}$. of lodine. Measure $25 \mathrm{cc}$. of this solution into a $500 \mathrm{cc}$. flask, and dilute to $200 \mathrm{cc}$; add $5 \mathrm{cc}$. of $50 \%$ phosphoric acid and a few drops of bromine; boil out the bromine; add $15-20$ drops of $5 \%$ sodium salicylate, cool, add 5-1o grams of sodium chloride, then add potassium iodide, and titrate the liberated iodine with approximately $0.005 \mathrm{~N}$ thiosulfate. This will establish the relation between "original iodine" and the $0.065 \mathrm{~N}$ thiosulfate, and from this the iodine equivalen of the potassiumt acid iodate can be found by adding a known volume of the acid iodate to $\mathrm{r}_{5} \mathrm{O} \mathrm{cc}$. of water containing potassium iodide, and $5 \mathrm{cc}$. of $50 \%$ phosphoric acid. When a small amount of iodic acid is in a solution which contains but a small amount of salts the reaction with potassium iodide is retarded and the end point of the titration with thiosulfate is uncertain. The addition of 5-10 grams of sodium chloride to such a solution accelerates the liberation of jodine and makes the end point sharp and accurate. The sodium chloride must not be added until after the solution has been boiled with bromine. 
added, and the fusion carried out as described, using 5 grams of sodium hydroxide. The determinations of iodine in the solutions of the fusion melt gave the following results:

$\begin{array}{ccccc}\begin{array}{c}\text { Iodine taken, } \\ \text { mg. }\end{array} & \begin{array}{c}\text { Cc. sodium } \\ \text { thiosulfate } \\ \text { required. }\end{array} & \begin{array}{c}\text { Iodine folind, } \\ \text { mg. }\end{array} & \begin{array}{c}\text { Error, } \\ \text { mg. }\end{array} & \begin{array}{c}\text { Error, } \\ \text { per cent. }\end{array} \\ 3.7 \mathrm{I3} & 36.95^{1} & 3.695 & -0.018 & -0.49 \\ 3.713 & 37.05^{1} & 3.705 & -0.008 & -0.21 \\ 3.713 & 37.05^{1} & 3.705 & -0.008 & -0.21 \\ 2.475 & 21.90^{2} & 2.48 \mathrm{I} & +0.006 & +0.24 \\ 2.475 & 21.85^{2} & 2.476 & +0.001 & +0.04 \\ 1.238 & 11.68^{3} & 1.235 & -0.003 & -0.24 \\ 1.238 & 11.75^{3} & 1.24 & +0.004 & +0.32 \\ 0.743 & 6.94^{4} & 0.735 & -0.008 & -1.07 \\ 0.743 & 7.00^{4} & 0.740 & -0.003 & -0.40 \\ 0.526 & 20.10^{5} & 0.530 & +0.004 & +0.75 \\ 0.526 & 20.08^{5} & 0.530 & +0.004 & +0.75 \\ 0.309 & 11.70^{5} & 0.309 & 0 & 0 \\ 0.309 & 11.80^{5} & 0.311 & +0.002 & +0.64 \\ 0.111 & 7.75^{6} & 0.111 & 0 & 0 \\ 0.111 & 7.78^{6} & 0.112 & +0.001 & +0.9 \\ 0.056 & 4.30^{7} & 0.056 & 0 & 0 \\ 0.056 & 3.93^{0} & 0.057 & +0.001 & +\mathrm{I} .8 \\ 0.031 & 2.50^{7} & 0.033 & +0.002 & +6.4 \\ 0.031 & 2.60^{7} & 0.034 & +0.003 & +0.7\end{array}$

To establish the standard of the sodium thiosulfate used, an iodine solution containing a known weight of iodine was accurately measured into a $500 \mathrm{cc}$. Erlenmeyer flask. Water was added until the volume was $200-250$ cc. Five cc. of $50 \%$ phosphoric acid were added and after adding a few drops of bromine the solution was shaken with a rotary motion until the bromine gave a distinct color to the solution. The bromine was boiled out, and IO-I5 drops of sodium salicylate were added. After cooling, 5-ro grams of sodium chloride and potassium iodide were added. The liberated iodine was titrated with the sodium thiosulfate. The weight of iodine measured into the flask divided by the number of cubic centimeters of thiosulfate required establishes the standard for original iodine. In boiling the bromine out of solution a hot plate is more convenient than a free flame as bumping is apt to occur.

Three commercial samples of desiccated thyroid when analyzed by this method gave the following results:

${ }^{1}$ Sodium thiosulfate $=0.1000 \mathrm{mg}$. original iodine.

${ }^{2}$ Sodium thiosulfate $=0.1133 \mathrm{mg}$. original iodine.

${ }^{3}$ Sodium thiosulfate $=0.1057 \mathrm{mg}$. original iodine.

${ }^{4}$ Sodium thiosulfate $=0.1044 \mathrm{mg}$. original iodine.

s Sodium thiosulfate $=0.0264 \mathrm{mg}$, original iodine.

"Sodium thiosulfate $=0.0144 \mathrm{mg}$. original iodine.

${ }^{7}$ Sodium thiosulfate $=0.013 \mathrm{I} \mathrm{mg}$. original iodine. 


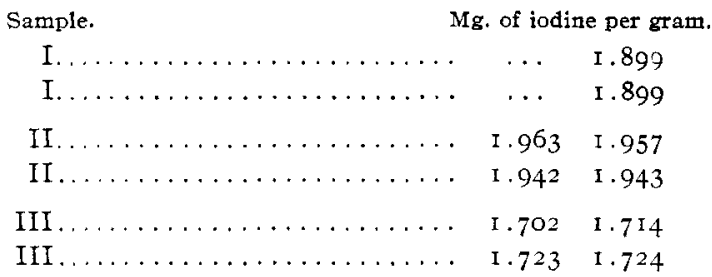

The writer wishes to express his appreciation to $\mathrm{Mr}$. A. W. Thomas for assistance during the course of this investigation.

\section{Summary.}

This paper on the determination of iodine establishes the conditions for the determination of iodine:

First, when present as a soluble iodide or in the uncombined form.

Second, when present with bromine, bromides, and chlorides.

Third, when present with interfering compounds, as copper, silver, mercury, nitrites, etc.

Fourth, when in organic combination.

Fifth, when present in small amounts, special reference being given to the determination of the iodine content of the thyroid gland, and to a qualitative test for the presence of iodine.

\section{NOTES.}

A Simple Automatic Mercury Pump.-This pump is made on the Töpler principle with a simple attachment whereby the mercury is raised and lowered by means of an ordinary water suction pump. It is shown in the diagram (Fig. I) with the modification of the Töpler pump introduced by Antropoff. ${ }^{1}$ A similar pump, but without this modification, has been in use for over four years and has proved satisfactory in every way.

$A, B, C$ are capillary tubes, $C$ being about $68 \mathrm{~cm}$. long. The part $D$ is shown in detail in Fig. 2. E is attached to a $\mathrm{P}_{2} \mathrm{O}_{5}$ tube and leads to the apparatus which is to be evacuated.

With the ordinary Töpler pump the evacuation is produced by alternately raising and lowering the mercury in $F$, by means of a movable vessel corresponding to $O$ which is raised and lowered. In this pump the same result is attained by alternately increasing and diminishing the air pressure over the mercury in $O$. This is achieved in the following manner: By evacuating through $S$ by means of a water suction pump, the mercury rises in $L$ and $C$. At the same time the air pressure over the mercury in $O$ diminishes. The mercury in $F$ falls. When the mercury in $L$ reaches the level $x_{1}$ the mercury in the cup $N$ is drawn up through the

' (hem. Ztg., 34, 974 (1910). 